\title{
Intermittent Exotropia, When to Recommend Glasses and When to Perform Surgery?
}

\author{
SHAIMAA H.M. SOKEER, M.Sc.; AHMED L. Aы, M.D. and EL-SAYED S. ARAFA, M.D. \\ The Department of Ophthalmology, Faculty of Medicine, Tanta University, Tanta, Egypt
}

\begin{abstract}
Aim of Work: The aim of this study is to determine which type of intermittent exotropia that may be corrected by glasses and which type that is best corrected by surgery and to evaluate the condition of binocular functions both before and after wearing glasses and before and after surgery.
\end{abstract}

Patients and Methods: Fifty patients ( 3 to 25 years) with intermittent exotropia were evaluated using a new scale to assess the level of control for both distance and near fixation. Near stereoacuity was evaluated with Tetmus Fly test. Diagnosis of IXT was based on history taking from patients or their parents and clinical examination.

Results: The 50 patients with intermittent exotropia had mean age of $9.56-\} 6.48$ with range between (3-25) years. Twenty six patients $(52 \%)$ were below 10 years and 24 patients (48\%) were above 10 years, 34 patients $(68 \%)$ were males and 16 patients $(32 \%)$ were females. The mean spherical was $-2.88 \pm 7.31$. The BCVA ranged from 0.40 to $1.0 \log$ MAR (mean $0.69 \pm 0.16$ ). Pretreatment distance deviation of exotropia ranged from 15 to $80 \mathrm{~A}$ (mean $38.40 \pm 16.14$ ). Twenty four patients $(48 \%)$ underwent surgery, glasses were prescribed for 8 patients $(16 \%)$ and over-correcting minus lenses were prescribed for 18 patients (36\%).

Conclusions: Over correcting minus lenses should be prescribed for IXT patients with the following criteria: high AC/A ratio, moderate to good control of exotropia, a temporizing measure for young patients waiting for surgery and sometimes for patients with undercorrection after surgery. Glasses should be prescribed for IXT patients with the following criteria; refractive error either astigmatism or myopia, moderate to good control of exotropia, and small angle of deviation. IXT patients with the following criteria should be corrected by surgery: Gradual loss of fusional control as evidenced by increasing frequency of the manifest phase of the strabismus, an increase in size of the basic deviation, development of suppression and decrease of stereoacuity.

Key Words: Intermittent exotropia-Glasses - Surgery.

Correspondence to: Dr. Shaimaa H.M. Sokeer, E-Mail: shaimaahady2012@ gmail.com

\section{Introduction}

EXODEVIATIONS ("exo" meaning "to exit" or "move out of") or divergent squint may be due to neurologic dysfunction, occurring as a result of certain obstacles to development or maintenance of binocular vision and/or defective action of the medial rectus muscles. Intermittent exotropia is an exodeviation intermittently controlled by fusional mechanisms. Exodeviations are much more common in a latent or intermittent form than are esodeviations. $60-70 \%$ of normal newborn infants have a transient exodeviation that resolves by 46 months of age [1-3]. Intermittent exotropia comprises about $75-90 \%$ of the cases of exotropia and is usually preceded by a stage of exophoria. It affects about $1 \%$ of the general population. Exodeviations occur more commonly in the Middle East, subequatorial Africa and East Asia than in the United States [4,5]

Etiology of IXT is thought to be due to defective fusion. In 1903, worth developed a theory that the essential cause of exotropia is a defect of the fusion faculty and indeed is a congenital total absence of the fusion faculty. High Accommodation Convergence to Accommodation (AC/A) ratio could have a role in intermittent exotropia. AC/A ratio is either normal or just slightly higher than normal in patients who have exotropia [6-8]. Refractive errors, in a patient with uncorrected myopia, less than normal accommodative effort is required during near vision thus causing decreased accommodative convergence this may cause an exodeviation to develop. This may lead to development of an exodeviation. The onset of IXT is thought to be in the first year of life. The characteristic features of IXT are unique; one eye deviates outward, typically when viewing a distant object, during periods of inattention, in bright sunlight or when the person is tired $[9,10]$ 


\section{Aim of the work:}

The aim of this study was to determine which type of intermittent exotropia that may be corrected by glasses and which type that is best corrected by surgery and to evaluate the condition of binocular functions both before and after wearing glasses and before and after surgery.

\section{Patients and Methods}

This is a prospective, institutional clinical trial study which took place at Tanta University Hospital, Ophthalmology Department in the period between April 2016 to October 2016 and included 50 patients. Diagnosis of IXT was based on history taking from patients or their parents and clinical examination. Diagnosis of IXT included history of repeated turning of one or the other eye outward.

Patients were considered to have IXT if the deviation was intermittently manifested at either distance or near during office examination. Informed consent was obtained from all participating adults and parents of participating children. All patients and their parents were asked in details about the age of onset, old photographs were required from parents for this purpose, interval between onset and examination and presence or absence of family history of the same condition, any previous intervention either surgery or glasses.

The following questions were asked, did its onset coincide with trauma or illness?, is the deviation constant or intermittent?, is it present for distance or near vision or both?, is it unilateral or alternating?, is it present only when the patient is inattentive or fatigued?, does the child close one eye?, is the deviation associated with double vision or eye strain? The following routine clinical assessments were undertaken at each visit; assessment of sensory function was done before visual acuity testing or measuring the angle of deviation to avoid dissociation of binocular vision by covering of one eye. Fusion was assessed by Worth four dot test and near steroacuity by Tetmus fly test, measuring of visual acuity both Uncorrected Visual Acuity (UCVA) and Best Corrected Visual Acuity (BCVA) monocular and binocular were measured using Landolt chart. Amblyopic patients were excluded from the study. Preschool children were tested using the illiterate E-test (the E-game).

Measuring the Angle of Deviation by Light Reflex Tests (Hirschberg method). Prolonged alternate cover test was used in patients with intermittent exotropia to suspend tonic fusional convergence. When there was significant angle variability or a significant distance/near discrepancy after prolonged alternate cover test, patch test was done. Patch Test was used to control the tonic fusional convergence to differentiate pseudo-divergence excess from true divergence excess and to reduce the angle variability and reveal the actual amount of deviation. Patch was placed over one eye for 1 hour to thoroughly dissociate the eyes, before removal of the patch the fellow eye was covered with an occluder. After the patch had been removed, the following measurement were recorded; Alternate prism cover at near with $+3 \mathrm{D}$ lens, Alternate prism cover at near without $+3 \mathrm{D}$ len, Alternate prism cover at distance without $+3 \mathrm{D}$ lens. It was important to prevent the patient from using both eyes together, even momentarily, since only a brief binocular exposure may be sufficient to again obscure the near deviation by fusional convergence. In simulated divergence excess (basic exotropia), rapid alternate covering revealed a markedly increased near deviation that matched or even exceeded the distance deviation, whereas with true divergence excess the near deviation remained unchanged. Cycloplegic refraction in children; Cyclopentolate $(1.0 \%)$ was the preferred drug for routine use in children. Spherical Equivilant (S.E) of both eyes was recorded. Full cycloplegic correction for myopia and astigmatism $<1.5 \mathrm{D}$, hyperopia $<3.5 \mathrm{D}$ was corrected after substraction of $2 \mathrm{D}$ to allow fusional convergence. Overcorrecting minus lenses were prescribed for other patients. AC/A ratio was determined to be high when a moderate disparity between near measurement obtained with or without +3.00D lenses persistence after occlusion.

Assessment of control by subjective methods; home control: The parents were told to keep a chart noting the control of deviation at home in terms of the percentage of waking hours the manifest deviation was noted at home. Office control: Good control for those patients who "breaks" only after cover test and resumes fusion rapidly without need for a blink or refixation. Fair control for those patients blinks or refixates to control the deviation after disruption with cover testing. Poor control for those patient who breaks spontaneously without any form of fusion disruption, or who does not spontaneously regain alignment despite blink or refixation.

Sensory evaluationby Worth Four Dot Test. This is a simple test utilizing red-green color dissociation. The apparatus for this test consists of a box containing four panes of glass, arranged in diamond formation, which are illuminated internally. The two internal panes are green, the upper 
one is red and lower one is white. The patient wears red and green goggles (as a convention red in front of right and green in front of left). The test was performed separately for distance and near vision. The interpretation of this test is as follows; if the patient sees all the four dots, normal binocular response with no manifest deviation (NRC with no heterotropia) Harmonious ARC with manifest squint. If the patient sees five dots, crossed diplopia with exotropia, red dots appear to the left of the green dots. If the patient sees three green dots, suppression of right eye. If the patient sees two red dots, suppression of left eye. Full cycloplegic correction for myopia and astigmatism $<1.5 \mathrm{D}$, hyperopia $<3.5 \mathrm{D}$ was corrected after substraction of $2 \mathrm{D}$ to allow fusional convergence. When the AC/A ratio was sufficiently high, minus lenses were used to decrease an exodeviation by stimulating accommodative convergence. In younger children with the convergence insufficiency type of exodeviation, minus lenses were prescribed. They were used as a temporizing measure; overcorrection with minus lenses may improve the quality of fusion and occasionally may even decrease the angle of deviation so that surgery may be deferred.

\section{Results}

This study was carried out on 50 patients with intermittent exotropia who met with the inclusion criteria. The mean age of patients was $9.56 \pm 6.48$ with range between (3-25) years. Twenty six patients $(52 \%)$ were below 10 years and 24 patients $(48 \%)$ were above 10 years, 34 patients $(68 \%)$ were males and 16 patients $(32 \%)$ were females. The mean spherical was $-2.88 \pm 7.31$. The BCVA ranged from 0.40 to $1.0 \log$ MAR (mean $0.69 \pm$ $0.16)$. The mean age of onset of exotropia was (3.20 \pm 3.43$)$ years. It ranged from 1.7 years to 12 years. Age at the time of treatment ranged from 3 to 25 years (mean $9.56 \pm 6.48$ ).

According to Baurian classification 28 patients (56\%) were of basic type, 10 patients $(20 \%)$ were of convergence insufficiency type, 8 patients $(16 \%)$ were of divergence excess type and 4 patients $(8 \%)$ were of pseudo-divergence excess type. Pretreatment distance deviation of exotropia ranged from 15 to $80 \Delta$ (mean $38.40 \pm 16.14$ ). Twenty four patients (48\%) underwent surgery, glasses were prescribed for 8 patients $(16 \%)$ and over-correcting minus lenses were prescribed for 18 patients (36\%). All patients completed 6 months follow-up period with periodic evaluation in 1 st week, 1 st month, 3 rd month and 6 th month. The distant angle measured by prolonged alternate prism cover test. The motor outcome was considered success when the distant angle after 6 months was orthotropic or $\geq 10 \Delta$ exo or $\geq 4 \Delta$ esophoria with fixation on a target at 6 meters (distance fixation).

The number of successful cases was 44 of 50 cases $(88 \%)$, the unsuccessful cases were $6(12 \%)$. Operated cases, at one week post-operative, 20 patients $(83.33 \%)$ out of 24 patients had successful outcome, 2 patients $(8.33 \%)$ had undercorrection with exotropia more than $10 \Delta, 2$ patients $(8.33 \%)$ had overcorrection with esotropia more than $10 \Delta$ The 2 overcorrected patients were followed-up till their distant angle improved to $+15 \Delta$ after 3 months and they were orthotropic by the 6 th month. One month after surgery, 20 patients $(83.33 \%)$ out of 24 patients had successful outcome, 2 patients $(8.33 \%)$ had undercorrection, 2 patients $(8.33 \%)$ had overcorrection with esotropia $20 \Delta$. At 3 months after surgery, we had the same results with improvement of esotropia of the two overcorrected cases from $20 \Delta$ to $15 \Delta$. At 6 months after surgery, 22 patients $(91.66 \%)$ out of 24 patients had successful outcome, 2 patients ( $8.33 \%$ ) had undercorrection and no patients had overcorrection. Over correcting minus lenses were prescribed for 18 patients, at one week after treatment, 4 patients (22.22\%) out of 18 patients had successful outcome. Fourteen patients $(87.88 \%)$ out of 18 patients had exotropia more than $10 \Delta$. One month after treatment, 10 patients out of 18 patients had successful outcome. Eight patients out of 18 patients had exotropia more than $10 \Delta$. Three month after treatment, all of patients had successful outcome. At this study, glasses were prescribed for 8 patients. At one week after treatment, all the patients had exotropia more than $10 \Delta$. One month after treatment, 4 patients $(50 \%)$ out of 8 patients had successful outcome. Four patients $(50 \%)$ out of 8 patients had exotropia more than $10 \Delta$. At 3 rd and 6th months after treatment, we had the same results. As shown in (Table 1), the successful cases had pre-operative distant angle ranged from $15 \Delta$ to $80 \Delta$ with mean deviation ( $37.73 \pm 17.37)$. Regarding overcorrecting minus lens therapy, the mean distance deviation before treatment was $(35 \pm 14.14)$, range from $20 \Delta$ to $60 \Delta$. The final post-treatment mean distance deviation (6 months after wearing overcorrecting minus lenses) was $(4.4 \pm 4.5)$ range from $(0-10 \Delta)$. All the cases had successful outcome. Regarding glasses, the mean distance deviation was (50.0 \pm 11.55$)$, range from $20 \Delta$ to $60 \Delta$ for successful cases. For unsuccessful cases the mean distance deviation before treatment was $(40 \pm 23.09)$, range $20 \Delta$ to $60 \Delta$. The final post-treatment mean distance deviation (6 months after wearing glasses) was $50 \pm 5.75 \Delta$ range from 0 to 10 for successful 
cases. The final post-treatment mean distance deviation (6 months after wearing glasses) was $20 \Delta$ for unsuccessful cases. As regards to the mean distant angle of exotropia, as shown in (Table 2), it differed significantly between successful and unsuccessful cases at the ${ }^{6 \text { th }}$ month after-treatment $\left(p\right.$-value $\left.<0.001^{*}\right)$. Pre-treatment control level of exotropia differed significantly between successful and unsuccessful cases ( $p$-value 0.016). Worth 4 Dot test was done for only 30 patients, 20 patients were excluded because their age was under 5 years. Change in the fusion state during the study period; before treatment, 24 patients $(80 \%)$ had fusion by Worth 4 Dot test and 6 patients (20\%) had suppression. At 6 months after treatment, 28 patients $(93.3 \%)$ had fusion by Worth 4 Dot test and 2 patients $(6.7 \%)$ had suppression. The percentage of patients who had fusion increased significantly from $(80 \%)$ to $(86.7 \%)$ at 3 months after-treatment, (93.3\%) 6 months after-treatment, ( $p$-value 0.046$)$.

As shown in (Table 3), no significant differences were found between patients with fusion before treatment and patients with suppression before treatment as regard the mean age at the onset of deviation ( $p$-value 0.06). On the other hand, the mean age at the time of treatment and the mean duration of exotropia at the time of treatment in patients with fusion or suppression was statistically significant ( $p$-value 0.028 and 0.048 respectively).
This indicates that the younger the patient with IXT, the better the motor outcome. Also the shorter the interval between the onset of the deviation and intervention, the better the motor outcome. Titmus fly test was done for only 30 patients, 20 patients were excluded because their age was under 5 years. Two patients of 30 patients demonstrated poor stereo acuity $(6.66 \%), 8$ patients $(26.66 \%)$ demonstrated moderate stereo acuity and 20 patients $(66.66 \%)$ had good stereo acuity.

Overcorrecting minus lenses were prescribed for 18 patients $(36 \%)$, all of them $(100 \%)$ had successful motor outcome at 6 months aftertreatment. Ten patients $(55.55 \%)$ were of convergence insufficiency type, 6 patients $(33.33 \%)$ were of basic type, 2 patients $(11.11 \%)$ were of divergence excess type.

As regard the control grade, 8 patients $(44.44 \%)$ had good control, 8 patients (44.44\%) had moderate control and 2 patients $(11.11 \%)$ had poor control. The mean distant angle of deviation before treatment was ( $35 \pm 14.14$ ), range from $20 \Delta$ to $60 \Delta, 4$ patients had central fusion, 2 patients with good stereoacuity and 2 patients with moderate stereoacuity. This indicates that patients with moderate to good control of exotropia, central fusion and good stereoacuity had successful motor surgical outcome.

Table (1): Relation between type of management and distant angle of deviation before treatment in successful versus unsuccessful cases.

\begin{tabular}{|c|c|c|c|c|c|c|c|c|c|}
\hline & \multicolumn{9}{|c|}{ Management } \\
\hline & \multicolumn{2}{|c|}{ Surgery } & \multicolumn{3}{|c|}{ Over correcting minus lens } & \multicolumn{4}{|c|}{ Glasses } \\
\hline & Successes & Un successes & \multicolumn{2}{|c|}{ Successes } & \multirow{2}{*}{$\begin{array}{c}\text { Un successes } \\
\text { No. } \%\end{array}$} & \multicolumn{2}{|c|}{ Successes } & \multicolumn{2}{|c|}{ Un successes } \\
\hline & No. & No. $\%$ & No. & $\%$ & & No. & $\%$ & No. & $\%$ \\
\hline - Distant angle before: & $(\mathrm{n}=22)$ & $(\mathrm{n}=2)$ & & & $(\mathrm{n}=0)$ & & & & \\
\hline Min.-max. & $15-80$ & $50-50$ & $20-6$ & & & $40-6$ & & $20-6$ & \\
\hline Mean \pm SD & $37.73 \pm 17.37$ & $50.0 \pm 0.0$ & 35.0 & & - & $50.0=$ & .55 & & .09 \\
\hline Median & 30.0 & 50.0 & 30.0 & & - & 50.0 & & 40.0 & \\
\hline $\mathrm{U}(\mathrm{p})$ & \multicolumn{2}{|c|}{$8.0(0.117)$} & \multicolumn{3}{|c|}{ - } & \multicolumn{4}{|c|}{$6.0(0.533)$} \\
\hline
\end{tabular}

Table (2): Relation between successes and distant angle.

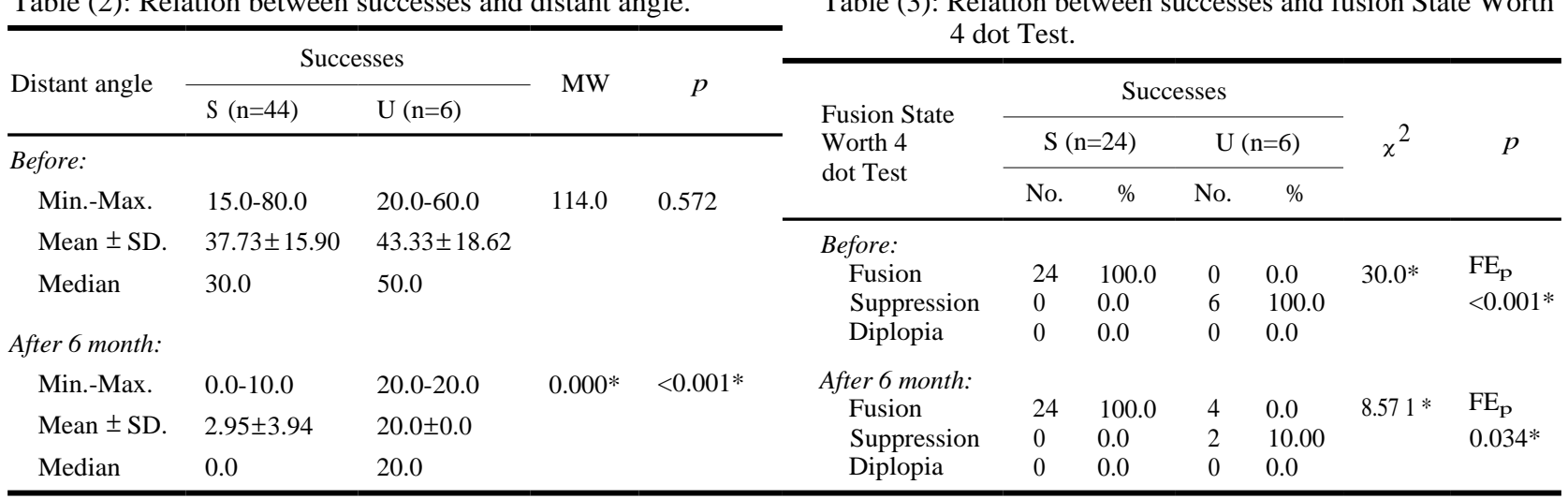


Table (4): Relation between successes and demographic data.

\begin{tabular}{|c|c|c|c|c|c|c|}
\hline & \multicolumn{4}{|c|}{ Successes } & \multirow{3}{*}{$\begin{array}{l}\text { Test } \\
\text { of } \\
\text { sig. }\end{array}$} & \multirow{3}{*}{$p$} \\
\hline & \multicolumn{2}{|c|}{$S(n=24)$} & \multicolumn{2}{|c|}{$\mathrm{U}(\mathrm{n}=6)$} & & \\
\hline & No. & $\%$ & No. & $\%$ & & \\
\hline \multicolumn{7}{|l|}{ Age (years): } \\
\hline Min.-Max. & \multicolumn{2}{|c|}{$3.0-25.0$} & \multicolumn{2}{|c|}{$11.0-22.0$} & $\mathrm{U}=$ & $0.002 *$ \\
\hline Mean \pm SD & \multicolumn{2}{|c|}{$8.50 \pm 5.94$} & \multicolumn{2}{|c|}{$17.33 \pm 5.09$} & $30.0^{*}$ & \\
\hline Median & \multicolumn{2}{|l|}{6.0} & \multicolumn{2}{|l|}{19.0} & & \\
\hline \multicolumn{7}{|l|}{ Age of onset: } \\
\hline Min.-Max. & \multicolumn{2}{|c|}{$0.17-11.0$} & \multicolumn{2}{|c|}{$3.0-12.0$} & $\mathrm{U}=$ & $0.007 *$ \\
\hline Mean \pm SD & \multirow{2}{*}{\multicolumn{2}{|c|}{$\begin{array}{l}2.68 \pm 3.03 \\
1.50\end{array}$}} & \multirow{2}{*}{\multicolumn{2}{|c|}{$\begin{array}{l}7.0 \pm 4.10 \\
6.0\end{array}$}} & $42.0^{*}$ & \\
\hline Median & & & & & & \\
\hline \multicolumn{7}{|l|}{ Iterval: } \\
\hline Min.-Max. & & \multicolumn{2}{|c|}{$8.0-13.0$} & $\mathrm{U}=$ & $0.003^{*}$ \\
\hline Mean \pm SD & \multicolumn{2}{|c|}{$5.82 \pm 5.18$} & \multicolumn{2}{|c|}{$10.33 \pm 2.25$} & $34.0^{*}$ & \\
\hline Median & & \multicolumn{2}{|l|}{10.0} & & \\
\hline
\end{tabular}

Table (5): Relation between type of management and distant angle of deviation before-treatment.

\begin{tabular}{|c|c|c|c|c|c|}
\hline & \multicolumn{5}{|c|}{ Management } \\
\hline & Surgery & \multicolumn{2}{|c|}{$\begin{array}{l}\text { Over correcting } \\
\text { minus lens }\end{array}$} & \multicolumn{2}{|c|}{ Glasses } \\
\hline & No. & No. & $\%$ & No. & $\%$ \\
\hline Distant angle before: & $(\mathrm{n}=24)$ & \multicolumn{2}{|c|}{$(\mathrm{n}=18)$} & \multicolumn{2}{|c|}{$(\mathrm{n}=8)$} \\
\hline Min.-Max. & \multirow{2}{*}{$38.75 \pm 16.96$} & \multirow{2}{*}{\multicolumn{2}{|c|}{$\begin{array}{l}20.0-60.0 \\
350+14.14\end{array}$}} & \multirow{2}{*}{\multicolumn{2}{|c|}{$20.0-60.0$}} \\
\hline Mean \pm SD & & & & & \\
\hline Median & 30.0 & \multicolumn{2}{|c|}{30.0} & \multicolumn{2}{|l|}{50.0} \\
\hline
\end{tabular}

Table (6): Effect of fusion state before-treatment on motor success rate.

\begin{tabular}{|c|c|c|c|c|}
\hline & \multicolumn{3}{|c|}{ Management } & \multirow{3}{*}{$\begin{array}{l}\text { Test } \\
\text { of } \\
\text { sig. }\end{array}$} \\
\hline & Surgery & $\begin{array}{c}\text { Over } \\
\text { correcting } \\
\text { minus lens }\end{array}$ & Glasses & \\
\hline & No. $\% \mathrm{I}$ & No. $\%$ & No. $\%$ & \\
\hline \multirow{4}{*}{$\begin{array}{l}\text { - Fusion State } \\
\text { W4 dot Test: } \\
\text { Fusion } \\
\text { Suppression }\end{array}$} & \multirow[t]{2}{*}{$(n=22)$} & \multirow[t]{2}{*}{$(n=4)$} & \multirow[t]{2}{*}{$(n=4)$} & $\mathrm{MC}_{p}=$ \\
\hline & & & & $13.231 * 0.002 *$ \\
\hline & $20 \quad 90.9$ & 100.0 & 0.0 & \\
\hline & 9.1 & $\begin{array}{ll}0 & 0.0\end{array}$ & 100.0 & \\
\hline
\end{tabular}

\section{Discussion}

Treatment for IXT typically consists of surgery on extraocular muscles either on the lateral rectus muscle of both eyes or on the medial rectus and lateral rectus muscle of one eye. Glasses for short or near sightedness or over correcting minus lenses can be tried. Exercises to strengthen the muscles may sometimes be used. The aim of treatment is often to normalise or improve ocular alignment whilst maintaining or improving binocular functions and stereoacuity [11]

Non-surgical management options include correction of refractive errors, over correcting minus lenses, part time occlusion and orthoptics. Significant refractive errors, especially astigmatism and anisometropic differences, should be corrected in patients with intermittent exodeviations to create sharp retinal images, which in turn increase the stimulus to fuse [12]. Full correction is advisable in myopic patients to maintain active accommodative convergence. Whether hypermetropia should be fully corrected, partially corrected, or corrected at all depends entirely on its degree, the age of the patient, and the AC/A ratio. Since correction of any hypermetropic refractive error will decrease the demand on accommodative convergence and thus increase the exodeviation, each patient should be evaluated on an individual basis. As a rule, we do not correct a hypermetropia of less than +2.00D sphere in children with exodeviations. In the older patient, correction of the hypermetropia is usually necessary to avoid refractive asthenopia, even though an underlying exophoria that was previously controlled by accommodative convergence then may become manifest and require therapy [12]

IXT patients with high AC/A ratio, overcorrecting minus lenses were prescribed to decrease an exodeviation by stimulating accommodative convergence. Jampolsky makes the point that $3 \mathrm{D}$ to $5 \mathrm{D}$ of accommodation stimulation with minus lenses is well tolerated by many children. He also observed that patients with orthophoria at near fixation and intermittent exotropia at distance fixation may become exophoric at near fixation under the influence of minus lenses. Jampolsky believes that surgical alignment of the eyes is facilitated by this change and advocates operating during this period [13]. Caltrider and Jampolsky reported that a significant number of patients from a group with intermittent exotropia treated by means of overcorrecting minus lenses manifested improved fusion as well as a decrease in their original deviation. This response persisted for as long as 1 year after therapy was discontinued in $70 \%$ of those who showed improvement [14]. We used this form of therapy in young IXT patients with high AC/A ratio and small deviations with moderate to good control and very young patients in whom surgical overcorrection can lead to amblyopia or loss of bifoveal fixation. Overcorrecting minus lenses were also prescribed as a temporizing measure for young patients waiting for surgery and sometimes for patients with undercorrection after surgery. Overcorrection with minus lenses may improve the quality of fusion and occasionally may even decrease the angle of deviation so that surgery may be deferred. Stimulation of accommodation with minus lenses is tolerated well by younger children, does not cause myopia, but may cause accommodative asthenopia as the child grows older and the amount of near work increases $[\mathbf{1 5 , 1 6}]$ 
Using non-surgical treatment as adjunct to surgery, pre-or post-operatively, or both, has been advocated by Coffey, France and VeronneauTroutman. Before surgery, treatment to eliminate suppression and teach awareness of diplopia is thought to increase the likelihood of obtaining cure [17-19]. The need for surgery was determined by the state of fusional control, the angle size of deviation, and the age of the patient. Surgical treatment of intermittent exotropia is directed at normalization of binocular function. There is good evidence for an improvement of distance stereoacuity after surgery. Signs of progression include gradual loss of fusional control as evidenced by increasing frequency of the manifest phase of the strabismus. Other signs of progression are development of a secondary convergence insufficiency, an increase in size of the basic deviation, development of suppression as evidenced by absence of diplopia during the manifest phase of the strabismus, decrease of stereoacuity.

The most desirable age at which surgery should be performed for intermittent exodeviations has been a matter of some dispute. Jampolsky prefers to delay surgery in visually immature infants to avoid overcorrection. In the interval, he reinforces fusion with minus lenses or prevents development of suppression by means of alternating occlusion [20]. On the other hand, Knapp is an advocate of early surgery for treatment of intermittent exotropia, a view shared by other authors [21]. In our study, we preferred to delay surgical intervention for intermittent exotropia in young children, since we shared Jampolsky's concern about the effects of a consecutive esotropia in a visually immature child. However, overcorrecting minus lenses were prescribed for those young patients. Surgery at an earlier age should be considered only if there is a rapid functional deterioration of fusional control in spite of nonsurgical therapy or if the deviation is constant.

This study was carried out on 50 patients with intermittent exotropia who met with the inclusion criteria. In our study, the successful motor rate was $88 \%$ that is, by definition, horizontal deviation of 0 to 104 (eso or exo) with fixation at accommodative target at 6 meters (distance fixation), 6 patients had unsuccessful motor outcome and all of them had residual exotropia, no patients had consecutive esotropia.

Before treatment, 24 patients (80\%) had fusion by Worth 4 Dot test and 6 patients $(20 \%)$ had suppression. 6 months after treatment, 28 patients $(93.3 \%)$ had fusion by Worth 4 Dot test and 2 patients $(6.7 \%)$ had suppression. The percentage of patients who had fusion increased significantly from $(80 \%)$ to $(86.7 \%)$ at 3 months after-treatment, (93.3\%) 6 months after-treatment, ( $p$-value 0.046). Stereoacuity deteriorates concomitantly with loss of fusional control in patients who have intermittent exodeviations. Awaya and coworkers and Ikeyama and Awaya made the astonishing observation that some patients with exotropia may preserve normal stereoacuity by rapid alternation [22]

In our study, the mean age at the time of treatment and the mean duration of exotropia at the time of treatment in patients with fusion or suppression was statistically significant ( $p$-value 0.028 and 0.048 respectively). This indicates that fusion state before-treatment had statistically significant effect on the success rate in motor outcome with higher success rates in cases with fusion. As regard the type of intervention, for treatment of IXT surgical versus non-surgical treatment, in our study, of 50 patients, 24 patients (48\%) underwent surgery with 22 patients $(91.66 \%)$ had successful motor outcome and 2 patients ( $8.33 \%$ ) had unsuccessful motor outcome, overcorrecting minus lenses were prescribed for 18 patients (36\%), all of them (100\%) had successful motor outcome at 6 months after treatment. Glasses were prescribed for 8 patients $(16 \%), 4$ patients $(50 \%)$ had successful motor outcome and 4 patients $(50 \%)$ had unsuccessful motor outcome.

In our study, as regards prognostic factors of surgical motor outcome, type of IXT according to Baurian classification was statistically insignificant ( $p$-value 1.000). Also the control grade of exotropia and fusion state by Worth 4 Dot test were statistically insignificant ( $p$-value 1.000) for both. On the other hand, distant angle of deviation before treatment and state of stereoacuity were statistically significant ( $p$-value $0.117,0.026$ respectively).

\section{Conclusion:}

The younger the patient with IXT, the shorter the interval between the onset of the deviation and intervention, the better the motor outcome. Fusion state before-treatment seems to increase the success rate in motor outcome. The earlier the treatment of IXT, the better the sensory outcome including binocular fusion and stereopsis. Over correcting minus lenses should be prescribed for IXT patients with the following criteria; high AC/A ratio, moderate to good control of exotropia, a temporizing measure for young patients waiting for surgery and sometimes for patients with undercorrection after surgery. Glasses should be prescribed for IXT patients with the following criteria; refractive error 
either astigmatism or myopia, moderate to good control of exotropia, small angle of deviation. IXT patients with the following criteria should be corrected by surgery; gradual loss of fusional control.

\section{References}

1- ARCHER S.M., SONDHI N. and HELVESTON E.M.: Strabismus in infancy. Ophthalmology; 96: 133, 1989.

2- NIXON R.B.: Incidence of strabismus in neonates. Am. J. Ophthalmology, 100: 798, 1985.

3- ARCHER S.M. and HELVESTON E.M.: Strabismus and Eye Movement Disorders. In Isenberg S.J. (ed). The eye in Infancy, Mosby, pg. 255, 1994.

4- GOVINDAN M., MOHNEY B.G., DIEHL N.N. and BURKE J.P.: Incidence and types of childhood exotropia: A population-based study. Ophthalmology, Jan., 112 (1): 104-8, 2005.

5- NOORDEN G.K. VON: Exodeviations. In: Binocular Vision and Ocular Motility 5 th ed., Mosby, pg. 343, 1996.

6- WORTH C.: Squint, its causes, pathology and treatment ed. 6. London, Bailliere, Tyndall and Cox, 1929.

7- COOPER J. and MEDOW N.: Intermittent Exotropia, basic and divergence excess type. Binoc Vis Eye Muscle Surg., 8: 185-216, 1993.

8- KUSHNER B.J.: Exotropic deviations: A functional classification and approach to treatment. Am. Ortho. J., 38: 81-93, 1988.

9- DONDERS F.C.: An essay on the nature and the consequences of anomalies of refraction. Ed. Oliver CA. Philadelphia 1899. P. Blakiston's Son and Co., pg. 59.

10-NOORDEN G.K. VON and AVILLA C.W.: Accomodative convergence in hypermetropia. Am. J. Ophthalmol., 110287, 1990.

11- ARCHER S.M., SONDHI N. and HELVESTON E.M.: Strabismus in infancy. Ophthalmology, 96: 133, 1989.

12-ZANONI D. and ROSENBAUM A.L.: A new method for evaluating distance stereoacuity. J. Pediatr. Ophthalmol. Strabismus., 28: 255, 1991.

13- FREEMAN R.S. and ISENBERG S.J.: The use of part time occlusion for early onset unilateral exotropia. J. Pediatr. Ophthalmol. Strabismus., 26: 94-6, 1989.

14- CALTRIDER N. and JAMPOLSKY A.: Overcorrecting minus lens therapy for treatment of intermittent exotropia. Ophthalmology, 90: 1160, 1983.

15- HUGONNIER R. and CRAYETTE-HUGONNIER S.: Strabismus, Heterophoria, Ocular Motor Paralysis. Clinical Ocular Muscle Imbalance. Translated and edited by Véronneau-Troutman S. St Louis, Mosby-Year Book, p. 201, 1969.

16- JAMPOLSKY A.: Characteristics of suppression in strabismus. Arch. Ophthalmol., 54: 683, 1955.

17- COFFEY, COFFEY B., WICK B., COTTER S., SCHARRE J. and HORNER D.: Treatment options in intermittent exotropia: A critical appraisal. Optometry and Vision Science, 69 (5): 386-404. [PubMed: 1594200], 1992.

18- FRANCE and FRANCE L.W.: The role of orthoptic therapy in exodeviations: A basis for orthoptic referral. American Orthoptic. Journal, 42: 52-64, 1992.

19- VERONNEAU-TROUTMAN and VERONNEAUTROUTMAN S.: Intermittent exotropia. International Ophthalmology Clinics, 11 (4): 114-9. [PubMed: 5155055], 1971.

20- HOLMES J.M., BIRCH E.E., LESKE D.A., FU V.L. and MOHNEY B.G.: New tests of distance stereoacuity and their role in evaluating intermittent exotropia. Ophthalmology, 114 (6): 1215-20, 2007.

21- KNAPP P.: Divergent deviations. In Allen J.H., ed: Strabismic Ophthalmic Symposium II. St Louis, Mosby-Year Book, p. 354, 1958.

22- AWAYA S., SUGAWARA M., KOMIYAMA K. and IKEYAMA K.: Studies on stereoacuity in four constant exotropes with good stereoacuity, with a special reference to the Titmus stereo. 


\section{الحول الوحشى المتقطع

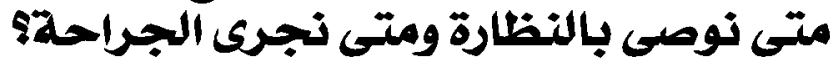

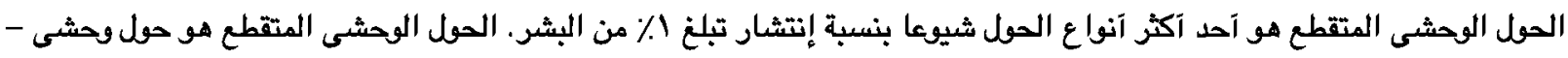

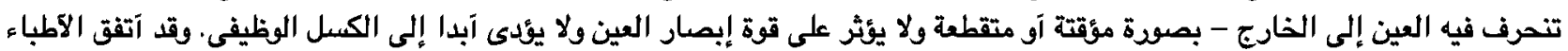

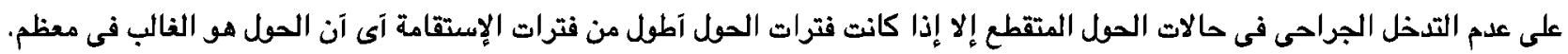

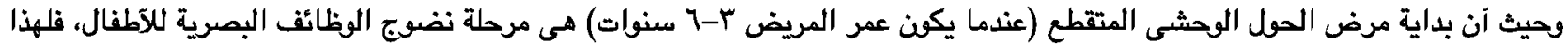

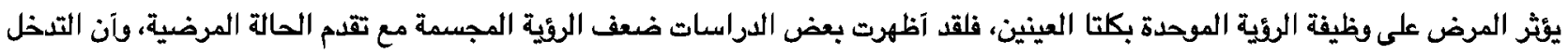

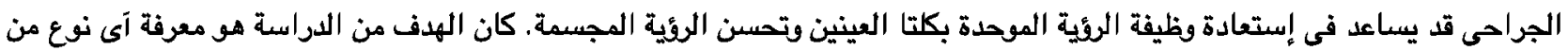

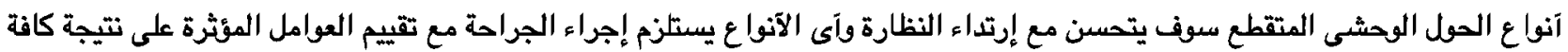

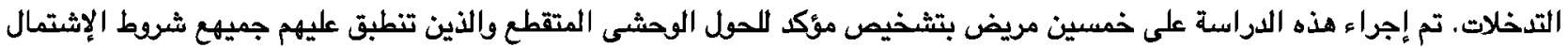

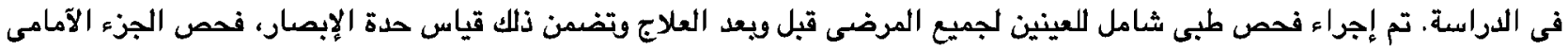

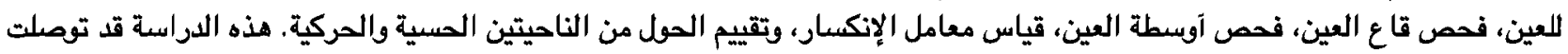

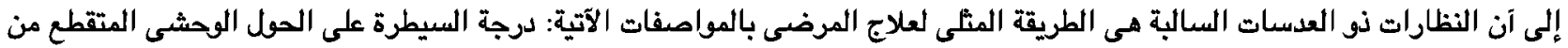

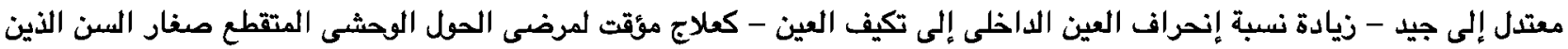

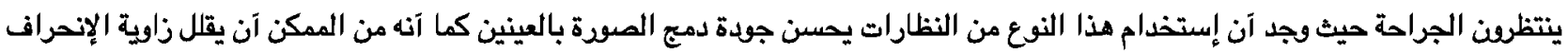

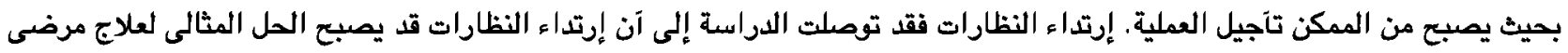

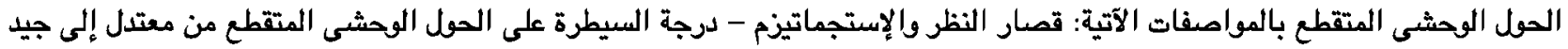

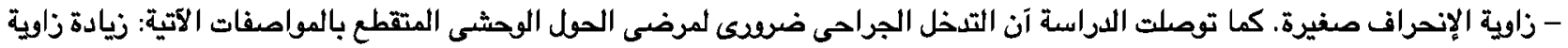
الإنحراف - حدوث تشييط مركزى - نقص الرئية المجسمة اللقريب بالعينين. 